\title{
Research on the Method of Capitalization of Entertainment Products in GDP Statistics
}

\author{
Weiguang Gong, Jiaojiao Hu*, Xiaobao Peng, Yang Li \\ The School of Public Affairs, University of Science and Technology of China, Hefei, China \\ Email: "gongwg2580@163.com
}

Received 21 March 2016; accepted 5 June 2016; published 8 June 2016

Copyright $(2016$ by authors and Scientific Research Publishing Inc.

This work is licensed under the Creative Commons Attribution International License (CC BY).

http://creativecommons.org/licenses/by/4.0/

(c) $\underset{\mathrm{EY}}{\mathrm{B}}$ Open Access

\begin{abstract}
It is one of directions of the reform about China's national economic statistics system to incorporate the intellectual property products into the GDP statistics, and the capital of intellectual property products is the first work to be incorporated into the GDP statistics. This article selected the entertainment industry as a microcosm of the development of the intellectual property economic, and accounted the capitalization of the original expenditure on entertainment industry to provide a reference for Chinese intellectual property products capital accounting and GDP accounting system reform.
\end{abstract}

Keywords

GDP Statistics, Entertainment Industry, Capital Accounting Method

\section{Introduction}

With the global economic development practice and economic theory constantly evolving, the mainstream of the system of national economic accounting (System of National Accounts: SNA-1993) has not accurately reflected the growth of national wealth, the differences in the quality of economic development or the true state of intellectual property and other intangible assets [1]. The current national economic accounting is basically the accounting of the tangible wealth, but it is proved that the intellectual property and other intangible wealth are more and more important to the economic development for a country. Data show that the box office in Chinese mainland totaled about 20.363 billion in the first half of 2015, compared with the same period last year, an increase of $48.17 \%$ [2]. At the same time, the major satellite of TV serial and TV variety also shows a strong ability of making money. However, the consumption expenditure behind income that is brought from box office revenue and audience rating has always been regarded as intermediate consumption, not included in the scope of Chinese GDP statistics.

*Corresponding author. 
In contrast, in 2013 the United States published the new GDP accounting method based on the framework of SNA-2008, a new method regarding spending on the entertainment, literature and art original as fixed assets into the GDP accounting. That means that the all expenditure on entertainment, literary and art original could be capitalized for enterprise and non-profit agencies, which undoubtedly will make the American GDP increase [3]. In addition, Australia and Canada also referred to the SNA2008 to repair its own GDP statistical system, ranking the intellectual property products that include the entertainment products as fixed assets into the GDP accounting.

The United States, Australia and other developed countries’ prior practices provide reference for China's entertainment products (one of intellectual property products) in the GDP statistical system of capital accounting work. However, from the point of view of the accounting method, the United States uses the future income of the net present value method to capitalize on its entertainment expenses, but the method containing the indicators is not suitable for Chinese national conditions [3]. Therefore, China begins to carry out the work of capital accounting on the entertainment industry expenditure, which must be based on China's national conditions and learn from the practice of some leading countries in the world to make a comprehensive choice.

Therefore, this paper, in the case of China's GDP statistical system facing reform, from the perspective of entertainment products, explores the capitalized accounting method of the entertainment products so as to provide some reference for the reforming of China's GDP statistical system. Specifically, according to the different characteristics of the entertainment products, the production cost method and the net present value method of future income are put forward for the capital accounting of different products. Two methods of accounting firstly combine the capital accounting method of intellectual property products and national economic accounting system to ensure the scientific nature of the GDP statistics.

\section{The Current Situation and Problems of the Accounting of Entertainment Products in China}

\subsection{The Scope of the Entertainment Industry in China and the Current Situation of Its Capital Accounting}

At present, as China still uses the SNA-1993 system (CSNA-2002), this system has not been related to the concept of intellectual property products. Entertainment products (film, television and radio programs, musical works) are dispersed under China’s national economy industry classification of culture, sports and entertainment. In the traditional accounting system, the entertainment is accounted as an industry, in the current GDP statistics system is not involved in the entertainment industry products of capital accounts [4]. With the rapid increase of intellectual capital, some intellectual property products such as entertainment products are consciously incorporated into the GDP accounting in China.

In the SNA-2008, entertainment, literature and art original are included in the category of intellectual property products. The entertainment, literature and art original including movies, TV and radio programs, literary works, musical works which including music videos, posters and brand names, technology and architectural drawings, model, paintings, sculpture, antiques, art and jewelry, photographs and pictures ten categories [5]. But in this article, the entertainment products refer to film, television and radio programs, (musical works that including musical video) these three categories.

Chinese entertainment industry has rapidly development, but the real effect that entertainment industry brings to economic growth has not been fully reflected. Trace back to the source, that's because Chinese entertainment products capital accounting is not accurate enough, the existing calculation method has been unable to meet the capital accounting for the entertainment products that be included in intellectual property products.

\subsection{The Capital Accounting of the Entertainment Industry in the United States GDP Statistics}

In 2013, the United States took the lead to follow the footsteps of the SNA2008, developed a new GDP accounting methods. The new GDP accounting system took the entertainment products into the scope of intellectual property products and considered the expenditure on entertainment products as a fixed capital formation included in GDP. This adjustment in the U.S.A. makes the expenditure of intangible assets tangible and capitalized, such as the cost of products in entertainment industry, which cannot be figured out by traditional counting method of GDP over a long period of time [6]. In view of the GDP data from the US Bureau of Economic Analysis website released in 2013, July 31, during the 10 years that from 2002 to 2012, if the United States ca- 
pitalize entertainment, literary and artistic original, the gross fixed capital formation about them will be from $\$ 576$ million rose to $\$ 743$ billion [3], so as to truly reflect the emerging economic form is leading by the economy innovation in the USA, highlighting the reality which economic growth appeared new wellspring in the United States.

After the United States has revolutionized GDP accounting method, it released a set of methods for the capitalization of the entertainment spending. According to the data from the Bureau of Economic Analysis, the United States mainly uses the method of net present value of future income to capitalize the production expenditure of entertainment products, the specific steps are as follows:

1) estimates of the total current revenues of licence fees, sales of commodities, ticket sales, etc.;

2) to deduct the cost of advertising, reproduction and other markets from the total current income, and calculate the net income;

3) to adjust the net income by using the investment ratio of the Bureau of Economic Analysis to include only the original product;

4) using the net present value adjustment factor to adjust the value of the net income, with the aim of deducing the current investment value from these new works of future earnings [7].

However, this method can only be used for reference to Chinese relevant research from the macro accounting method, and China still does not have the conditions to implement this method. Such as some accounting indexes in the accounting method are not clear: in the first step, it is unknown that how to estimate of the total income for the current period; in the second step, what is included within other market costs; and in the step 4, what are the net present value adjustment factor concretely. For these questions, the US Bureau of Economic Analysis does not explain, I have not found a reasonable explanation by consulting the relevant data.

China has become the world's second largest economic entity and the world economic growth engine. In China, it has become a major choice to implement a new round of high level of opening up, promote the implementation of "The Belt and Road Initiative" and efforts to build a new pattern of world development. Either the United States or other countries that take the lead in implementing the SNA-2008, they have capitalized accounting for entertainment products from different angles of and included it in the GDP statistics. Under this background, China also began to adjust GDP accounting method. Accelerate intellectual property products as a kind of fixed asset into Chinese GDP accounting, this is not only an encouragement and affirmation for the economic development of intellectual property, but also the cause of domestic intellectual property undertaking docking international intellectual property undertaking. Entertainment products as a kind of intellectual property products, the contribution it made to the development of the national economy is growing. It is one of the keys that underestimated to capitalize accounting entertainment products and joined it into the national economic accounting in order to optimize the system of GDP statistic in current reform of GDP accounting system in China.

\section{The Method of Capital Accounting on Entertainment Products}

\subsection{The Basis of Capitalizing in Entertainment Products}

Although China's GDP statistics system is not related to the concept of capitalizing for intellectual property products, but in view of the United States, Canada, Australia and other countries have been carried out related work, it is enough to illustrate the capitalization accounting work for intellectual property products is feasible [8]. And after the announcement of the SNA-2008, the Organization for Economic Cooperation and Development (OECD), Eurostat and the Australian Bureau of statistics took the lead in organizing the staff to research calculation method for gross fixed asset formation of intellectual property products, and introduced the Handbook on deriving capital measures of intellectual property products [9]. The manual, collected the data and capital accounting method of some representative countries' intellectual property products, which provided the theoretical and practical support for the capital accounting of entertainment products in China. In addition, although China has not explicitly carried out the work of capitalizing the entertainment products, but the assessment of the intangible assets like entertainment products has been carrying out in China. So, China has the conditions to begin to capitalize of entertainment products now.

\subsection{The Systematic Introduction of the Capital Accounting for the Entertainment Products}

As mentioned above, some countries and OECD organizations have provided reference for capitalizing enter- 
tainment products from the perspective of practice and theory in China. Considering the reality of China and basing on the learning from other countries practice, I believe that the following four directions can be set out to develop suitable for capitalizing China's entertainment products:

a) The purchase price of the original, if traded.

b) The purchase prices of similar originals.

c) The production costs of the original.

d) The discounted net present value of future receipts.

According to the available information, it can be concluded that the assets of the intellectual property products can be divided into the purchased assets and the assets that are self produced. And the production of the film, television and radio program belongs to the assets of subsistence production. For self-sufficiency of the assets, it should be applied to the total production costs to estimate its capital value, which in accordance with the original production costs to determine its capital value. Production cost method conduct practical accounting through two methods, one is micro method, namely to investigate enterprises and government departments, to get the cost estimate of production of fixed assets. The second is macro method, which the total output of the original is obtained by multiplying labor input and the wage rate of per unit of labor input and other costs, then which subtracted from the part of the value that produced for sale, that's capital total value. It is worth nothing that the cost of production of films, television and radio programmers should include royalty payments that paid for the use of other originals.

In addition, the net present value of future benefits for musical works with a established royalty flow system is the most appropriate. All the proceeds of original should be taken into account when determining the value of the original.

\section{The Supporting Measures of Capitalizing for Entertainment Products}

\subsection{The Feasibility of New Accounting Methods}

The capitalization of intellectual property products into the GDP accounting system conforms to the trend of world economic development. 21st century is an era of innovation, how to reflect the value of innovation in the GDP has become the focus of attention by all countries. The 40th session of the UN Statistical Commission established a new national economic accounting international statistical standards SNA-2008, in the SNA-2008, the entertainment products and other intangible assets are seen as intellectual property products and incorporated into classification of fixed assets, and included in GDP accounting, which shows the great value of intellectual property [10].

China's rapid development of the cause of intellectual property, and take related products into GDP assets accounting scope could encourage and promote the development of local knowledge-based economy, promote local economic innovation consciousness, provide a powerful driving force for China's economy development to science and technology innovation mode. In the current, China national economic accounting system is based on SNA-1993 as a reference, cannot meet the needs of the development of today's society, capitalizing the entertainment products and putting into the national economic accounting system is an inevitable choice.

\subsection{Contribution of Practice to the New Accounting Methods}

Once the new accounting methods introduced, which will be conducive to improving China's GDP growth. The average rising rate from 1929 to 2012 has risen $0.1 \%$ through the adjustment of capitalizing intellectual property products in the USA, which 2010 GDP growth up from 2.4\% to 2.5\%. In 2011, GDP growth will remain unchanged at $1.8 \%$, the 2012 GDP growth up from $2.2 \%$ to $2.8 \%$ [3]. After China capitalizes intellectual property products, the total GDP will be improved whatever applying any methods, production method, revenue method and expenditure method.

Capitalization of intellectual property products is conducive to the protection of intellectual property. Entertainment products is the object of the intellectual property after all, if the economic value of entertainment products are expressed in the form of money, which will certainly promote the protection of intellectual property. The economic value of entertainment products produced in production, host, play and other activities. To make clear economic value of entertainment products that each activity corresponding to, which is conducive to coordinate the relationship among the authors, other copyright user and other interested party, promote the author and other intellectual property user to protect their legitimate interests [11]. 
In addition, the capitalization of intellectual property products not only directly provide services to the copyright disputes in judicial practice, but also is conducive to the judicial and arbitration institutions reasonably and fairly trial copyright disputes and accelerate handling speed, improve the efficiency of handling cases.

Capitalization of intellectual property products is conducive to the innovation and development of intellectual property. The form of currency prices to perform the intangible entertainment products directly reflects the value of intellectual property. Driven by this kind of economic benefits, people's enthusiasm for the creation and innovation of the entertainment industry will also be improved. At the same time, the social resources flow further reasonably flow, so as to improve Chinese socialist commodity market, and promote the healthy development of the cultural market. And then it promotes international culture, education, science and technology exchange, and is conducive to the further development of China's international trade [12]. In the end, Chinese intellectual property cause will be pushed to a new development level.

\subsection{Problems in the Implementation of New Accounting Methods}

First, the workload of data collection increased. Due to intellectual property products that are not included in the scope of fixed assets currently, corresponding detailed foundation data is lacking. It is bound to increase basic data collection workload after the launch of new GDP accounting method, which aggravates the burden of the staff of the relevant statistical work.

Secondly, it is difficult to ensure that the data source is true and complete. At present, local GDP contribution value is linked to performance directly, if incorporating intellectual property products as fixed assets into GDP accounting, which may repeat due to false total local GDP statistics caused serious local water phenomenon at present [13]. Data source is the basis of all statistical work, China's current total GDP estimate based mostly. One of the main reasons is the authenticity and comprehensiveness of the data source cannot be guaranteed. The intellectual property products are intangible products, it's much more difficult in value measurement compared to tangible fixed assets. If the data source cannot be guaranteed, then the final accounting data has no value whatsoever. What's more, untrue data could mislead the data user and lead to the error of judgment [14].

Anyway, relative to physical assets, because the weak correspondence between the cost of intangible assets and the intrinsic value of intangible assets, and intangible cost measurement is not accurate and other factors, which makes the cost method in the practice of entertainment products capital accounting very inconvenient.

\section{Summary and Outlook}

At present, China works in full swing for the intellectual property products into the GDP statistics, but the new accounting system has not been introduced. Needless to say, the GDP accounting system reform must be included in the intellectual property products; the consequent problem is the capital accounting methods of intellectual property products. This article embarks from the Chinese entertainment industry status, draws on the experience of the practice of capital accounting from other countries, and provides a tentative approach to the capitalization of the products in China's entertainment industry. That will fill the blank in capital accounting theory of intellectual property in China, and provide some reference to China's GDP accounting system reform.

At present, China is in the critical period of economic transformation. Capitalizing for intellectual property products, which could help to grasp of China's economic reform and development of the whole process, improves the effectiveness of the formulation and implementation of relevant economic policies, better guides and coordinates economic development in each place. In addition, improving the capital accounting of intellectual property products in the GDP statistics lays a solid foundation to master more intellectual property of international rules in the world for China.

This paper focused on the study of the capital accounting methods in entertainment products, rarely mentioned into the GDP statistical work after accounting. Therefore, integrating and standardizing GDP statistics closeout to make sense of the entertainment capital of the product can be demonstrated. China should draw lessons from the SNA-2008, divide statistical units and institutions in more detail, implement each of the statistical work to each staff specifically, firm up the division and responsibilities of each statistical personnel.

Intellectual property products capital accounting is a new subject in the field of intellectual property; there are few related researches in China. And specific to the entertainment industry, almost no one gets involved. For the research direction of the capital accounting method of entertainment products, I think that we can proceed from the following aspects: 
First, broaden the scope of asset accounting. Some other intangible assets similar to the nature of the entertainment products are also incorporated into the scope of the entertainment products, so as to reflect that the entertainment products are essential to economic development in the process of economic growth. However, to refine the work sector or broaden the scope of asset accounting requires a lot of human resources. Therefore, training a group of professional staff in accordance with the new GDP statistics system is a priority. Moreover it is essential to strive to achieve statistical offices and statisticians to inject fresh blood, link conformity, and standardized GDP statistics.

Second, improve the relevant legal system. The emergence of new things is often accompanied by the birth of the new rules. Entertainment products capital accounting method and the whole intellectual property products capital accounting methods require relevant rules and regulations to ensure their smooth implementation. Therefore, to improve the current legal system and related supporting measures can provide a good external environment for the entertainment product capital accounting and the inclusion of GDP statistics.

Third, make efforts to increase cooperation in international exchanges. In recent years, with the export of "HuanZhen Biography", "Lang Ya Bang" and other national productions, the norms that China passed have represented that the introduction of the US drama and Korean drama has been broken. We are in a good Internet age. We should increase the intensity of exchanges and cooperation, sign international treaties on entertainment products, and develop the capitalization of entertainment products accounting method jointly with other contracting countries to avoid controversies about the import and export of entertainment products in the international arena.

\section{References}

[1] Zheng, Q.S. (2015) The Study of Capital Measurement Methods after Intellectual Property Products into the National Economic Accounting System. Financial Economy, 48, 81- 82.

[2] Peng, F.L. (2015) In the First Half of the Film Market Review: The Movie Box Office Outbreak.

[3] Zeng, W.Y. and Wang, K.K. (2014) The Contents, Influence and Enlightenment on the Latest Adjustment of American GDP Accounting. Statistical Research, 3, 9-15.

[4] National Economic Accounting Department (2010) China Non Economic Census Annual Gross National Product Accounting Method (Revised Edition). China Statistics Press, Beijing, 117.

[5] SNA2008, Chinese Version, 174.

[6] Planning and Development Department of the State Intellectual Property Office (2014) Intellectual Property Products and the Adjustment of China's GDP Accounting System. Patent Statistics, 5, 8.

[7] US Bureau of Economic Analysis (2013) Preview of the 2013 Comprehensive Revision of the National Income and Product Accounts: Changes in Definitions and Presentations. http://www.bea.gov/scb/pdf/2013/03\%20March/0313_nipa_comprehensive_revision_preview.pdf

[8] The Research Group of “The Revision of "SNA” and the Reform of China's National Economic Accounting System reform” (2012) The Revision of SNA and Its Enlightenment to the Reform of China's National Economic Accounting System. Statistical Research, 6, 9.

[9] Chang, X.Y. and Wang, Y. (2012) The Capital Accounting Methods for Intellectual Property Products: Handbook on Deriving Capital Measures of Intellectual Property Products. China Statistics, 11, 27.

[10] Wu, Y.Y. (2013) The Research on Improvement of the Path and Content of China's National Economic Accounting System-Based on the Perspective of SNA2008. Thesis, Guangdong University of Finance \& Economics, Guangzhou.

[11] Li, L.M. and Liu, H.B. (2012) The Strategic Significance of Intellectual Property Industry. Technology Promotion Development, 7, 54 .

[12] Wu, H.D. (2013) Study on the Reform and Development of Intellectual Property System. Publishing House of Economic Science, Beijing, 85.

[13] Sun, X.X. (2011) Study on the Method of GDP Estimation in China. Thesis, Shanghai Jiao Tong University, Shanghai.

[14] Chen, C.Y. (2009) Research on Valuation Methods of Intangible Assets. Thesis, Anhui University of Science and Technology, Hefei. 